Supplement of Atmos. Chem. Phys., 21, 1565-1580, 2021

https://doi.org/10.5194/acp-21-1565-2021-supplement

(C) Author(s) 2021. This work is distributed under

the Creative Commons Attribution 4.0 License.

(c) (1)

Supplement of

\title{
Mass accommodation and gas-particle partitioning in secondary organic aerosols: dependence on diffusivity, volatility, particle-phase reactions, and penetration depth
}

Manabu Shiraiwa and Ulrich Pöschl

Correspondence to: Manabu Shiraiwa (m.shiraiwa@uci.edu) and Ulrich Pöschl (u.poschl@mpic.de)

The copyright of individual parts of the supplement might differ from the CC BY 4.0 License. 

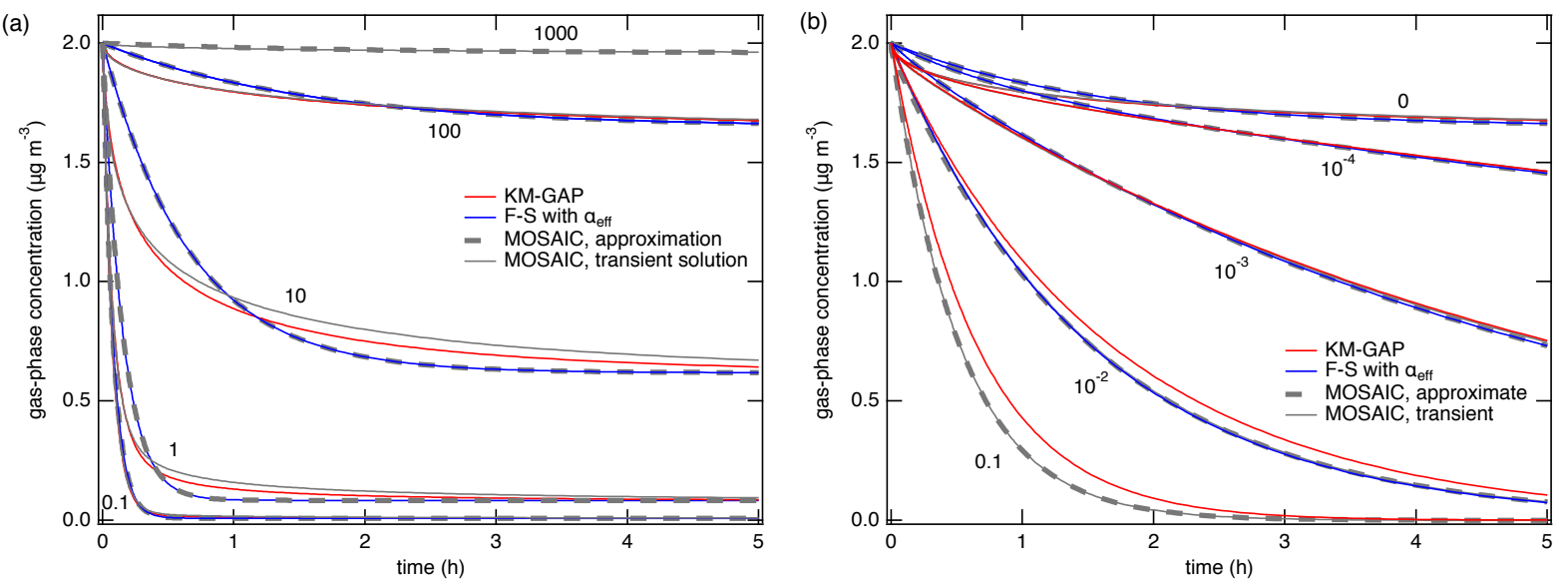

2 Figure S1. Temporal evolution of the gas phase concentration of organic compounds interacting

3 with semisolid seed aerosol particles under the same conditions as in Fig. 2 but with $\alpha_{\mathrm{s}}=0.1$

4 instead of 1. (a) Non-reactive partitioning of compounds with different volatilities $\left(C^{0}=0.1\right.$ to

$\left.51000 \mu \mathrm{g} \mathrm{m}^{-3}\right)$ and (b) partitioning of semi-volatile compounds $\left(C^{0}=100 \mu \mathrm{g} \mathrm{m}^{-3}\right)$ undergoing

6 particle-phase reactions with different first-order loss rate coefficients $\left(k_{\mathrm{b}}=10^{-4}\right.$ to $\left.0.1 \mathrm{~s}^{-1}\right)$. The

7 red lines are simulated with KM-GAP and the blue lines are simulated by an aerosol dynamic

8 model that employs the Fuchs-Sutugin approximation with $\alpha_{\text {eff }}$ for non-reactive partitioning (a)

9 and for reactive uptake (b). The gray lines represent the MOSAIC approximate (dashed) and 10 transient solutions (solid) (Zaveri et al., 2014). 